\title{
Aldosterone escape during blockade of the renin-angiotensin- aldosterone system in diabetic nephropathy is associated with enhanced decline in glomerular filtration rate
}

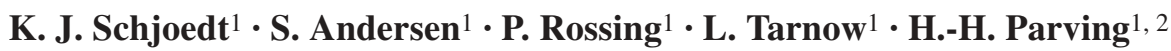 \\ ${ }^{1}$ Steno Diabetes Center, Gentofte, Denmark \\ ${ }^{2}$ Faculty of Health Science, University of Aarhus, Denmark
}

\begin{abstract}
Aims/hypothesis. It has been suggested that aldosterone plays a role in the initiation and progression of renal disease independently of arterial blood pressure and plasma angiotensin II levels. We evaluated the influence of plasma aldosterone levels on progression of diabetic nephropathy during long-term blockade of the renin-angiotensin-aldosterone system.

Methods. A total of 63 hypertensive patients with type 1 diabetes and diabetic nephropathy were treated with losartan, $100 \mathrm{mg}$ once daily, for a mean follow-up period of 35 months. Plasma aldosterone, GFR, albuminuria and 24-h blood pressure were determined at baseline and at regular intervals during the study.

Results. Patients were divided according to their increasing or decreasing levels of plasma aldosterone during long-term losartan treatment in an escape group $(n=26)$ and a non-escape group $(n=37)$. In the escape group, aldosterone levels increased from (geometric mean $[95 \% \mathrm{CI}]) 57 \mathrm{pg} / \mathrm{ml}(43-76 \mathrm{pg} / \mathrm{ml})$ at 2 months, to $102 \mathrm{pg} / \mathrm{ml}(78-134 \mathrm{pg} / \mathrm{ml})$ at the end of the study
\end{abstract}

$(p<0.01)$. The corresponding levels in the non-escape group were $83 \mathrm{pg} / \mathrm{ml}(69-102 \mathrm{pg} / \mathrm{ml})$ and $49 \mathrm{pg} / \mathrm{ml}$ (40-60 pg/ml; $p<0.01)$. The median rate of decline in GFR was $5.0 \mathrm{ml} \cdot \mathrm{min}^{-1} \cdot$ year $^{-1}$ (range $0.4-15.9 \mathrm{ml} \cdot \mathrm{min}^{-}$ 1. year-1 $^{-1}$ in the escape group, compared with $2.4 \mathrm{ml} \cdot \mathrm{min}^{-1}$.year ${ }^{-1}\left(-1.6\right.$ to $11.0 \mathrm{ml} \cdot \mathrm{min}^{-1} \cdot$ year $\left.^{-1}\right)$ in the non-escape group $(p<0.005)$. The increase in plasma aldosterone correlated with the rate of decline in GFR $\left(r^{2}=0.19, p<0.001\right)$, corresponding to a decline in GFR of $1.5 \mathrm{ml} \cdot \mathrm{min}^{-1}$.year ${ }^{-1}$ for every two-fold increase in plasma aldosterone. Pre-treatment and treatment values of plasma aldosterone were not related to albuminuria or to changes in albuminuria during the study.

Conclusions/interpretation. Our data suggest that aldosterone escape during long-term blockade of the renin-angiotensin-aldosterone system is associated with an enhanced decline in GFR in patients with type 1 diabetes and diabetic nephropathy.

Keywords Aldosterone escape · Angiotensin II receptor blockade $\cdot$ Diabetes $\cdot$ Diabetic nephropathy . Renin-angiotensin-aldosterone system
Received: 6 May 2004 / Accepted: 12 July 2004

Published online: 17 November 2004

(C) Springer-Verlag 2004

K. J. Schjoedt (๘)

Steno Diabetes Center, Niels Steensens Vej 2, 2820 Gentofte, Denmark, E-mail: kjos@steno.dk Fax: +45-44438234

Abbreviations: ACEI, angiotensin-converting enzyme inhibitor · AngII, angiotensin II · ARB, angiotensin II receptor antagonists · RAAS, renin-angiotensin-aldosterone system

Conflict of interest: Hans-Henrik Parving received honoraria or consulting fees from Merck, AstraZeneca, BMS, Sanofi-Synthelabo and Pfizer, and grant/research support from Merck and Sanofi-Synthelabo.

\section{Introduction}

In recent years it has become clear that aldosterone is not only responsible for the maintenance of fluid and electrolyte balance, but that it should be considered a hormone with widespread effects on the vasculature, the heart and the kidneys $[1,2]$.

In long-term clinical trials with blockade of the renin-angiotensin-aldosterone system (RAAS) by angiotensin-converting enzyme inhibitors (ACEIs) or angiotensin II (AngII) receptor antagonists (ARBs) [3, $4,5]$ or the combination of both [5], plasma aldosterone levels have been shown to increase in some patients after an initial reduction or unchanged level (the aldosterone escape phenomenon). 
Table 1. Baseline characteristics of 63 hypertensive patients with type 1 diabetes and diabetic nephropathy

\begin{tabular}{|c|c|c|}
\hline & Aldosterone escape group $(n=26)$ & Aldosterone non-escape group $(n=37)$ \\
\hline Sex (women : men) & $12: 14$ & $13: 24$ \\
\hline Age (years) & $43.0 \pm 10.1$ & $44.1 \pm 8.9$ \\
\hline Duration of diabetes (years) & $31.3 \pm 7.0$ & $33.0 \pm 9.9$ \\
\hline Duration of nephropathy (years) ${ }^{\mathrm{a}}$ & $11(1-26)$ & $13(1-22)$ \\
\hline Retinopathy (simplex : proliferative) & $5: 21$ & $7: 30$ \\
\hline 24-h diastolic blood pressure $(\mathrm{mm} \mathrm{Hg})$ & $79 \pm 9$ & $80 \pm 9$ \\
\hline Albuminuria $(\mathrm{mg} / 24 \mathrm{~h})^{\mathrm{b}}$ & $1347(973-1865)$ & $1016(776-1329)$ \\
\hline GFR $\left(\mathrm{ml} \cdot \mathrm{min}^{-1} .1 .73 \mathrm{~m}^{-2}\right)$ & $86 \pm 25$ & $88 \pm 23$ \\
\hline S-creatinine $(\mu \mathrm{mol} / \mathrm{l})$ & $103 \pm 35$ & $104 \pm 24$ \\
\hline Protein intake $\left(\mathrm{g} \cdot \mathrm{kg}^{-1} .24 \mathrm{~h}^{-1}\right)$ & $0.99 \pm 0.30$ & $1.16 \pm 0.49$ \\
\hline P-renin $(\mu \mathrm{U} / \mathrm{ml})^{\mathrm{b}}$ & $29(20-40)$ & $48(33-69)^{\mathrm{c}}$ \\
\hline
\end{tabular}

Patients were divided into two groups according to the presence (escape group) or absence (non-escape group) of aldosterone escape, i.e. an increase in plasma aldosterone from the visit after 2 months of losartan treatment to the end of the study.

The aim of our study was to investigate the prevalence and impact of the aldosterone escape phenomenon during long-term ARB treatment in hypertensive patients with type 1 diabetes and diabetic nephropathy, and to evaluate the influence of plasma aldosterone levels before and during renoprotective treatment on decline in GFR.

\section{Subjects and methods}

Patients and study design. The study was a prospective intervention trial designed to investigate the long-term renoprotective effects of losartan in 54 patients with type 1 diabetes and diabetic nephropathy, homozygous for the insertion (I) or deletion (D) allele of the $A C E / I D$ polymorphism. The trial has previously been published [6]. In addition, 14 heterozygous (ID) patients were studied using the same protocol (Table 1).

All antihypertensive medication was withdrawn for at least 4 weeks prior to enrolment. Thereafter, patients were treated with losartan at a dose of $50 \mathrm{mg}$ once daily for the first 2 months and $100 \mathrm{mg}$ once daily for the remainder of the study. All patients fulfilled the compliance criterion of taking more than $85 \%$ of the study medication. Additional antihypertensive treatment, i.e. diuretics, calcium channel blockers and alpha blockers, were given in an attempt to achieve a target blood pressure of below 135/85 mm Hg. Dietary intake of protein and salt was not restricted. GFR, albuminuria and 24-h blood pressure were determined at baseline and at regular intervals thereafter, as described previously [6]. Laboratory variables Oincluding plasma aldosterone, AngII and renin were determined at baseline as well as at the first (after 2 months) and last visit during losartan treatment [6]. Plasma aldosterone was measured using a commercially available radioimmunoassay (Coat-a-Count; Diagnostic Products, Los Angeles, Calif., USA). Five patients were excluded due to missing values.

"Aldosterone escape" was defined as an increase in plasma aldosterone from 2 months of ARB treatment to the end of the study.
Data are expressed as $n$, means \pm SD unless stated otherwise. $\mathrm{P}$, plasma; S, serum; a Median (range); ${ }^{\mathrm{b}}$ geometric mean $(95 \%$ $\mathrm{CI}) ;{ }^{\mathrm{c}} p<0.05$ vs escape group

The study was performed according to the principles of the Declaration of Helsinki and was approved by the ethical committee of Copenhagen County. All patients gave informed consent.

Data analysis. Comparisons of normally or log-normally distributed parameters were performed using Student's $t$ test. Relations between putative predictors of progression $\left(\mathrm{HbA}_{1} \mathrm{c}\right.$, albuminuria, blood pressure, plasma aldosterone) and rate of decline in GFR were evaluated by multiple linear regression analysis. A $p$ value of less than 0.05 was considered significant (two-tailed test). Correction for multiple comparisons was not carried out as suggested previously [7]. However, to calculate a simple correction for multiple comparisons (Bonferroni correction), $p$ values can be multiplied by five (number of comparisons). Data were analysed using SPSS 11.5 (SPSS, Chicago, Ill., USA).

\section{Results}

Aldosterone escape occurred in 26 patients, corresponding to $41 \%$ (95\% CI 29-53\%). Patients were divided into two groups according to the presence (escape group) or absence (non-escape group) of aldosterone escape. There were no significant differences between the two groups at baseline, except for a lower plasma renin concentration in the escape group (Tables 1 and 2).

Overall plasma aldosterone was (geometric mean [95\% CI] $77 \mathrm{pg} / \mathrm{ml}(62-95 \mathrm{pg} / \mathrm{ml})$ at baseline, compared with $72 \mathrm{pg} / \mathrm{ml}(61-84 \mathrm{pg} / \mathrm{ml})$ at 2 months and $67 \mathrm{pg} / \mathrm{ml}(56-80 \mathrm{pg} / \mathrm{ml})$ at the end of the study (NS). In the escape group there was an initial decrease in plasma aldosterone levels from $88 \mathrm{pg} / \mathrm{ml}$ $(62-125 \mathrm{pg} / \mathrm{ml})$ at baseline to $57 \mathrm{pg} / \mathrm{ml}(43-76 \mathrm{pg} / \mathrm{ml})$ at 2 months $(p<0.002)$, after which aldosterone levels 
Table 2. Plasma aldosterone, plasma renin, plasma AngII, 24-h blood pressure, serum potassium, albuminuria, U-potassium, U-sodium, and $\mathrm{U}-\mathrm{K}: \mathrm{Na}$ ratio in 63 patients with type 1 diabetes and diabetic nephropathy

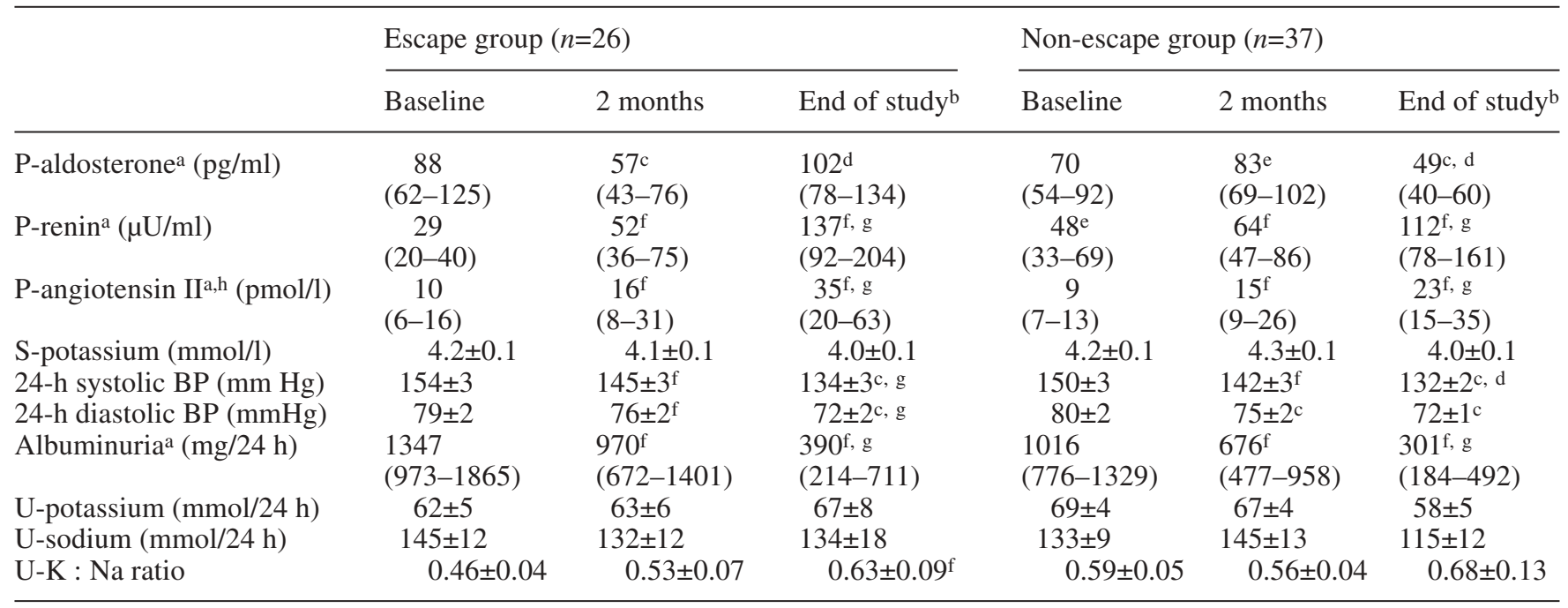

Patients were divided into two groups according to the presence (escape group) or absence (non-escape group) of aldosterone escape during long-term treatment, i.e. an increase in plasma aldosterone from 2 months of losartan treatment until the end of the study.

increased to $102 \mathrm{pg} / \mathrm{ml}(78-134 \mathrm{pg} / \mathrm{ml})$ by the end of the study $(p<0.01$; Table 2$)$. In the non-escape group there was an initial increase (NS) in plasma aldosterone levels from $70 \mathrm{pg} / \mathrm{ml}(54-92 \mathrm{pg} / \mathrm{ml})$ at baseline to $83 \mathrm{pg} / \mathrm{ml}(69-102 \mathrm{pg} / \mathrm{ml})$ at 2 months, after which aldosterone levels decreased to $49 \mathrm{pg} / \mathrm{ml}(40-60 \mathrm{pg} / \mathrm{ml})$ by the end of the study ( $p<0.01$; Table 2$)$.

The median (range) rate of decline in GFR during 35 months of treatment with losartan was $3.0 \mathrm{ml}$. $\mathrm{min}^{-1}$.year-1 $\left(-1.6\right.$ to $\left.15.9 \mathrm{ml} \cdot \mathrm{min}^{-1} \cdot \mathrm{year}^{-1}\right)$. In the escape group the rate of decline in GFR was $5.0 \mathrm{ml}$. $\mathrm{min}^{-1}$.year ${ }^{-1}\left(0.4-15.9 \mathrm{ml} \cdot \mathrm{min}^{-1} \cdot \mathrm{year}^{-1}\right)$ as compared with $2.4 \mathrm{ml} \cdot \mathrm{min}^{-1}$.year ${ }^{-1}\left(-1.6\right.$ to $11.0 \mathrm{ml} \cdot \mathrm{min}^{-1} \cdot$ year $\left.^{-1}\right)$ in the non-escape group $(p<0.005)$.

No correlations were found between aldosterone levels at baseline or after 2 months of ARB treatment and rate of decline in GFR. An elevated plasma aldosterone level at the end of the study was correlated with an increased rate of decline in GFR $\left(r^{2}=0.17\right.$, $p=0.001)$. The change in plasma aldosterone from the visit at 2 months to the end of the study correlated with the rate of decline in GFR $\left(r^{2}=0.19, p<0.01\right)$. Furthermore, changes in plasma aldosterone from baseline to the end of the study correlated significantly, although more weakly, with rate of decline in GFR $\left(r^{2}=0.07, p<0.05\right)$.

Albuminuria and 24-h blood pressure were reduced to a similar extent in the two groups $(p<0.05$; Table 2). The expected increase in serum renin and AngII was seen in both groups (NS between groups; Table 2). $\mathrm{HbA}_{1} \mathrm{c}$ was not related to plasma aldosterone levels.
Data are expressed as means \pm SEM unless stated otherwise. P, plasma; S, serum; U, urinary. a Geometric mean $(95 \% \mathrm{CI})$; b mean follow-up time 35 months (range: 24-42 months); ${ }^{\mathrm{c}} p<0.002$ vs baseline; ${ }^{\mathrm{d}} p<0.001$ vs 2 months; ${ }^{\mathrm{e}} p<0.05$ vs escape group; ${ }^{\mathrm{f}} p<0.05$ vs baseline; ${ }^{\mathrm{g}} p<0.05$ vs 2 months; ${ }^{\mathrm{h}} n=14$ in escape group and $n=17$ in non-escape group

Pre-treatment and treatment values of plasma aldosterone were not related to albuminuria or to changes in albuminuria during the study.

A multiple linear regression analysis revealed that mean arterial blood pressure and changes in aldosterone were independent predictors of rate of decline in GFR. An increase in mean arterial blood pressure of $10 \mathrm{~mm} \mathrm{Hg}$ corresponds to a decline in GFR of $1.82 \mathrm{ml} \cdot \mathrm{min}^{-1}$.year-1, and a two-fold increase in plasma aldosterone levels corresponds to a decline in GFR of $1.50 \mathrm{ml} \cdot \mathrm{min}^{-1} \cdot$ year $^{-1}$ ( $r^{2}$ [adjusted] $=0.32$ ). $\mathrm{HbA}_{1} \mathrm{c}$, albuminuria, GFR at baseline, and ACEI/D polymorphism were not significant variables in the model.

At the end of the study, 49 patients (22 in the escape group vs 27 in the non-escape group) received additional antihypertensive treatment, i.e. thiazid or loop diuretics were prescribed to 46 patients (21 vs 25), 14 patients received calcium channel blockers (5 vs 9), and three received an alpha-blocking agent (2 vs 1) (NS between groups).

\section{Discussion}

Aldosterone escape during long-term RAAS blockade occurred in $41 \%$ of our patients. The rate of decline in GFR was higher in these patients. Since the correlation between GFR decline and plasma aldosterone and aldosterone escape is based on single measurements, an even stronger correlation due to regression dilution bias is suggested [8]. Furthermore, the study revealed a mean rate of decline in GFR of only 
$3 \mathrm{ml} \cdot \mathrm{min}^{-1}$.year-1 during renoprotective treatment with losartan.

The mechanisms involved in the aldosterone escape phenomenon are poorly understood. Incomplete RAAS blockade, lack of treatment compliance, variation in sodium intake, potassium homeostasis, pharmacogenetics, differences in the AngII production at tissue level, and the sensitivity of the adrenal gland to AngII may all be involved. Our study demonstrated that the two groups were alike with respect to demographic, clinical and laboratory data except for a lower plasma renin concentration in the escape group. A lower circulating level of renin has been reported to reflect increased intrarenal syntheses of AngII [9]. The enhanced initial reduction in aldosterone with later escape to pre-treatment levels is consistent with this concept. Since our data demonstrate that the circulating levels of renin and AngII were about the same in the two groups, we can rule out major differences in compliance to losartan treatment. Furthermore, the pattern of additional antihypertensive treatment, including diuretics, was similar in the two groups, as was plasma potassium levels and urinary $\mathrm{K}$ : Na ratios. This indicates that the salt intake did not differ between groups. The $I / D$ polymorphism of the $A C E$ gene has been shown to play a role in the aldosterone escape phenomenon [3], but since the distribution of the $I / D$ alleles in the two groups did not differ, this can hardly be the explanation for the present finding.

Previous studies have suggested that the escape phenomenon occurs within 1 year [4], which may imply that the exposure in our study to elevated aldosterone levels was long-standing. Unfortunately, no systematic measurements of plasma aldosterone or urinary aldosterone excretion were carried out repeatedly during our 3-year study.

Recent clinical trials have indicated that aldosterone blockade may have an antiproteinuric effect in type 2 diabetes mellitus. By adding spironolactone to the ACEI treatment for 24 weeks in 13 patients with type 2 diabetes and early nephropathy who developed aldosterone escape during 40 weeks of ACEI therapy, Sato et al. [4] found a further reduction in albuminuria compared with ACEI monotherapy. Patients who did not develop aldosterone escape $(n=27)$ were not treated with spironolacton, so the effect in these patients is unknown. Epstein et al. [10] recently compared the effect of enalapril monotherapy, eplerenone (selective aldosterone receptor antagonist) monotherapy, or a combination of both in a total of 215 patients with type 2 diabetes and mild to moderate hypertension and microalbuminuria. After 24 weeks of treatment, eplerenone was more effective $(62 \%)$ in reducing albuminuria than enalapril (45\%), and the combination was even more effective (74\%) than either monotherapy despite similar reductions in systolic and diastolic blood pressure in all groups.

In summary, our findings suggest that aldosterone escape during long-term RAAS blockade is associated with an enhanced decline in GFR in patients with type 1 diabetes and diabetic nephropathy. Clinically, this phenomenon may be an important contribution to the reduced renoprotective effect of RAAS blockade. Consequently, aldosterone blockade should be considered in patients with suboptimal renoprotection during RAAS blockade.

Acknowledgements. The authors would like to thank Dr Deinum for performing the aldosterone assays. We would also like to thank T.R. Juhl, B.V. Hansen, B.R. Jensen, U.M. Smidt and I.-L. Rossing for laboratory assistance.

\section{References}

1. Epstein M (2001) Aldosterone and the hypertensive kidney: its emerging role as a mediator of progressive renal dysfunction: a paradigm shift. J Hypertens 19:829-842

2. Epstein M (2001) Aldosterone as a determinant of cardiovascular and renal dysfunction. J R Soc Med 94:378-383

3. Cicoira M, Zanolla L, Rossi A et al. (2001) Failure of aldosterone suppression despite angiotensin-converting enzyme (ACE) inhibitor administration in chronic heart failure is associated with ACE DD genotype. J Am Coll Cardiol 37:1808-1812

4. Sato A, Hayashi K, Naruse M, Saruta T (2003) Effectiveness of aldosterone blockade in patients with diabetic nephropathy. Hypertension 41:64-68

5. McKelvie RS, Yusuf S, Pericak D et al. (1999) Comparison of candesartan, enalapril, and their combination in congestive heart failure: randomized evaluation of strategies for left ventricular dysfunction (RESOLVD) pilot study. The RESOLVD Pilot Study Investigators. Circulation 100:1056-1064

6. Andersen S, Tarnow L, Cambien F et al. (2003) Long-term renoprotective effects of losartan in diabetic nephropathy: interaction with ACE insertion/deletion genotype? Diabetes Care 26:1501-1506

7. Rothman KJ (1990) No adjustments are needed for multiple comparisons. Epidemiology 1:43-46

8. MacMahon S, Peto R, Curtler J et al. (1990) Blood pressure, stroke and coronary heart disease, part 1: prolonged differences in blood pressure: prospective observational studies corrected for the regression dilution bias. Lancet 335:765-774

9. Lansang MC, Price DA, Laffel LM et al. (2001) Renal vascular responses to captopril and to candesartan in patients with type 1 diabetes mellitus. Kidney Int 59:1432-1438

10. Epstein M, Buckalew V, Martinez F et al. (2002) Antiproteinuric efficacy of eplerenone, enalapril, and eplerenone/ enalapril combination therapy in diabetic hypertensives with microalbuminuria. Am J Hypertens 15 [Suppl 1]:A24 (Abstract) 